\title{
Association between serum adropin levels and isolated coronary artery ectasia in patients with stable angina pectoris
}

\author{
(iD) Buğra Özkan, (1) Özcan Örsçelik, (D) Hatice Yıldırım Yaroğlu*, (D) Şenay Balcı*, \\ (D) Mert Koray Özcan, (1) Ahmet Çelik, (1) Ísmail Türkay Özcan
}

Departments of Cardiology, and *Biochemistry, Faculty of Medicine, Mersin University; Mersin-Turkey

ABSTRACT

Objective: Dilation of one or more coronary artery segments to a diameter at least 1.5 times that of a normal adjacent segment is referred to as coronary artery ectasia (CAE). Adropin is a protein involved in endothelial function and is shown to have a protective effect on the regulation of cardiac functions. Atherosclerosis and endothelial dysfunction play an important role in the development of CAE. The aim of this study was to investigate the association between serum adropin levels and isolated CAE.

Methods: Patients with stable angina pectoris who underwent coronary angiography (CAG) between August 2017 and July 2018 were evaluated prospectively. A total of 92 subjects were included in the study-40 patients over 18 years old and diagnosed with isolated CAE based on CAG findings and a control group of 52 patients.

Results: Serum adropin level was found to be significantly lower in the isolated CAE group compared to the control group (1019.57 pg/mL and $1151.10 \mathrm{pg} / \mathrm{mL}$, respectively, $\mathrm{p}=0.010$ ). The isolated CAE group also exhibited a significantly higher mean platelet volume than that in the control group (10.75 fL and $10.17 \mathrm{fL}$, respectively, $\mathrm{p}=0.011)$.

Conclusion: Our results show that there is an association between low serum adropin level and isolated CAE. (Anatol J Cardiol 2019; 22: 250-5)

Keywords: endothelial dysfunction, coronary artery ectasia, adropin

\section{Introduction}

Coronary artery ectasia (CAE) is defined as the dilation of one or more coronary artery segments to a diameter at least 1.5 times that of a normal adjacent segment (1). Angiographically proven CAE has been reported at a prevalence of up to $5 \%(2,3)$. In more than half of patients with CAE, ectasia has been shown to develop secondary to severe coronary artery stenosis. In the absence of coronary artery disease, ectasia is referred to as isolated CAE (4). Even without accompanying obstructive coronary artery disease, endothelial dysfunction and abnormal coronary artery dilation in CAE may cause ischemic symptoms such as angina pectoris and can even lead to infarction.

The endothelium is one of the most important determinants of blood flow in the coronary arteries (5). The endothelium produces certain extracellular matrix components and is involved in the regulation of vascular tone and permeability, maintenance of the balance between coagulation and fibrinolysis, and prolif- eration of vascular smooth muscle (6). Endothelial dysfunction is considered a primary pathology in the development of atherosclerosis and other vascular pathologies (7). Endothelial function can be assessed either by directly using isolated vessels or by indirect means such as measuring endothelium-dependent vasodilation responses (8).

Adropin is a peptide that is released from the brain, liver, heart, and coronary arteries, and it plays a role in endothelial function (9). Adropin regulates the enzymes involved in hepatic lipogenesis in the liver and the regulator of lipogenesis, peroxisome proliferator-activated receptor gamma (PPARy), in adipose tissue (9). Studies have shown that low serum adropin level causes endothelial dysfunction.

Although the relationship between CAE and various molecules known to be associated with endothelial dysfunction has been demonstrated previously $(10,11)$, there is no study in the literature examining the relationship between the serum adropin level and isolated CAE. The aim of this study was to investigate the association between serum adropin levels and isolated CAE.

Address for correspondence: Dr. Buğra Özkan, Mersin Üniversitesi Tıp Fakültesi, Kardiyoloji Anabilim Dalı,

Çiftlikköy Mah. 33140 Yenişehir/Mersin-Türkiye

Phone: +90 5065306229 E-mail: bugraozkan@yahoo.com

Accepted Date: 09.08.2019 Available Online Date: 30.10.2019

(C) Copyright 2019 by Turkish Society of Cardiology - Available online at www.anatoljcardiol.com DOI:10.14744/AnatolJCardiol.2019.90349 


\section{Methods}

Patients with stable angina pectoris who underwent coronary angiography (CAG) between August 2017 and July 2018 were studied prospectively. The power analysis was performed using G Power 3.0.10 for Windows. In order to find the difference between patient and control groups to be statistically significant for the adropin parameter, 31 cases in each group are sufficient with 0.05 Type I error and $80 \%$ power. Patients presenting to the cardiology outpatient clinic with complaints of angina pectoris underwent CAG, if appropriate, based on evaluation with noninvasive methods such as transthoracic echocardiography (TTE), stress test, myocardial perfusion scintigraphy, and multislice computed tomography. CAG was performed via the femoral or radial artery using the Judkins method. The results of CAG were examined by two different cardiologists with no knowledge of the study. The subjects included in the study were divided into an isolated CAE group (group 1) and the control group (group 2). Isolated CAE was defined for CAG findings of dilation in a segment of any major coronary artery to at least 1.5 times the diameter of an adjacent segment, without a lesion causing more than $50 \%$ stenosis. Based on its topographic features, CAE can be divided into four types: Type 1: diffuse ectasia in 2-3 arteries; Type 2: diffuse ectasia in 1 artery and localized ectasia in other arteries; Type 3: diffuse ectasia in only 1 artery; and Type 4: localized and segmental ectatic lesions (12). All of the patients in the control group had stable angina pectoris and were referred for CAG due to a positive stress test or high clinical suspicion of CAD. Normal coronary arteries, defined as no visible disease or luminal irregularity (less than $50 \%$ ) as judged visually on CAG, were identified in all patients in the control group. Patients with acute/chronic infectious or inflammatory diseases, history of coronary artery bypass grafting, acute coronary syndrome within the last 3 months, chronic kidney disease (serum creatinine $>2.0 \mathrm{mg} / \mathrm{dL}$ ), severe valvular heart disease, malignancies, and congestive heart failure (with symptoms or left ventricular ejection fraction $<45 \%$ ) were excluded from the study.

Patients' histories were investigated and the presence or absence of risk factors such as diabetes mellitus (DM), smoking, hypertension, and hyperlipidemia and the medications used were recorded. Patients with a blood pressure $>140 / 90$ $\mathrm{mm} \mathrm{Hg}$ and those using antihypertensive drugs were considered to have hypertension. Patients under treatment for DM and those with a fasting blood glucose level $>126 \mathrm{mg} / \mathrm{dL}$ in two consecutive measurements were accepted as having DM. The height $(\mathrm{cm})$ and weight $(\mathrm{kg})$ of subjects were recorded and their body mass index (BMI) was calculated using the formula height $(\mathrm{cm}) /$ weight $^{2}(\mathrm{~kg})$. TTE results and laboratory parameters were recorded from hospital records. Approval was obtained for the study from the university clinical research ethics committee. Informed consent forms were obtained from all patients and control subjects.

\section{Sample collection}

By venipuncture, $10-\mathrm{mL}$ venous blood samples were collected into tubes containing no anticoagulant. Immediately after collection, the samples were centrifuged at $1000 \times \mathrm{g}$ for $15 \mathrm{~min}$ utes and the resulting serum was stored at $-20^{\circ} \mathrm{C}$ until measurement of serum adropin levels. Adropin levels were measured by enzyme-linked immunosorbent assay (ELISA) using a Human $A D$ (adropin) ELISA kit (Elabscience E-EL-H5307).

Statistical analyses were done using SPSS version 21.0 (SPSS Inc., Chicago, IL, USA) package software. The ShapiroWilk test was used to assess for normal distribution of biochemical parameters in the patient and control groups. The data were found to be normally distributed. Student's t-test was used to evaluate differences in biochemical measurements between patient and control groups. In addition, binary logistic regression analysis was conducted to identify risk factors in the patient and control groups. The model was reduced using stepwise multiple variable logistic regression analyses, and we eliminated potential risk markers using likelihood ratio tests. Variables with $p$ values $<0.2$ in univariate analysis were used in the multiple variable analysis. We used this approach to prevent multicollinearity, especially due to the small number of observations (13). Receiver operating characteristic (ROC) curve analysis was done to determine the discriminative power of adropin in the patient and control groups and identify a cut-off value for this parameter (MedCalc ${ }^{\circledR}$ Version 9.2.0.1). We selected cut-off points based on highest Youden's index in order to maximize both sensitivity and specificity (Youden's index: sensitivity+specificity-1) (14).

Categorical variables were expressed as percentage; numerical variables with normal distribution (parametric) were expressed as mean \pm standard deviation. $P$ values $<0.05$ were accepted as statistically significant.

\section{Results}

A total of 92 subjects were included in this study, including 40 patients who were over 18 years old and diagnosed with isolated CAE based on CAG findings and a control group of 52 patients with normal coronary arteries. The demographic data of the participants are shown in Table 1. There were no significant differences between the groups in terms of sex, age, DM, hypertension, smoking, hyperlipidemia, or BMI. Table 2 presents the laboratory parameters of patients with and without isolated CAE. Serum adropin level was found to be significantly lower in the isolated CAE group than that in the control group $(1019.57 \mathrm{pg} / \mathrm{mL}$ and $1151.10 \mathrm{pg} /$ $\mathrm{mL}$, respectively, $\mathrm{p}=0.010$ ). The isolated CAE group also exhibited a significantly higher mean platelet volume (MPV) compared to the control group ( $10.75 \mathrm{fL}$ and $10.17 \mathrm{fL}$, respectively, $\mathrm{p}=0.011)$.

In ROC curve analysis, an adropin cut-off value of $1234 \mathrm{pg} / \mathrm{mL}$ had $85 \%$ sensitivity and $42 \%$ specificity as an indicator of isolated CAE. The area under the curve for this relationship was 0.649 , and the $95 \% \mathrm{Cl}$ was $0.54-0.74$ (Fig. 1). 


\begin{tabular}{|c|c|c|c|}
\hline Variables & $\begin{array}{l}\text { Isolated CAE } \\
\text { group } \\
(n=40)\end{array}$ & $\begin{array}{l}\text { Control } \\
\text { group } \\
(n=52)\end{array}$ & $P$ value \\
\hline Sex $(n, \%)$ males & $27(67.5)$ & $30(57.7)$ & 0.392 \\
\hline Age (year) & $56.9 \pm 7.6$ & $55.2 \pm 10.2$ & 0.364 \\
\hline Diabetes mellitus, $\%$ & $8(20)$ & $12(23.1)$ & 0.723 \\
\hline Hypertension, \% & $12(30)$ & $13(25)$ & 0.593 \\
\hline Hyperlipidemia, \% & $8(20)$ & $8(15.4)$ & 0.563 \\
\hline Smoking, \% & $9(22.5)$ & $13(25)$ & 0.780 \\
\hline ACEI/ARB use, $\%$ & $6(15)$ & $9(17.3)$ & 0.758 \\
\hline CCB use, $\%$ & $7(17.5)$ & $6(11.5)$ & 0.414 \\
\hline BB use, $\%$ & $6(15)$ & $6(11.5)$ & 0.091 \\
\hline Aspirin use, $\%$ & $11(27.5)$ & $9(17.3)$ & 0.240 \\
\hline Statin use, \% & $7(17.5)$ & $6(11.5)$ & 0.416 \\
\hline BMI $\left(\mathrm{kg} / \mathrm{m}^{2}\right)$ & $26.2 \pm 2.4$ & $25.5 \pm 2.1$ & 0.154 \\
\hline \multicolumn{4}{|l|}{ Markis classification } \\
\hline Type 1, \% & $6(15)$ & & \\
\hline Type 2, \% & $17(42.5)$ & & \\
\hline Type 3, \% & $13(32.5)$ & & \\
\hline Type 4, \% & $4(10)$ & & \\
\hline
\end{tabular}

Table 2. Biochemical features of patients and controls

\begin{tabular}{|lccc|}
\hline Variables & $\begin{array}{c}\text { Isolated CAE } \\
\text { group } \\
\text { (n=40) }\end{array}$ & $\begin{array}{c}\text { Control } \\
\text { group } \\
\text { (n=52) }\end{array}$ & $\begin{array}{c}\boldsymbol{P} \\
\text { value }\end{array}$ \\
\hline Creatinin (mg/dL) & $0.85 \pm 0.17$ & $0.83 \pm 0.16$ & 0.688 \\
Na (mg/dL) & $140.0 \pm 4.0$ & $140.4 \pm 2.7$ & 0.892 \\
K (mg/dL) & $4.40 \pm 0.49$ & $4.44 \pm 0.38$ & 0.674 \\
MPV (fL) & $10.75 \pm 0.78$ & $10.17 \pm 0.76$ & $\mathbf{0 . 0 1 1}$ \\
WBC (103/ $/ \mathrm{LL}$ ) & $7.80 \pm 1.92$ & $7.60 \pm 1.80$ & 0.863 \\
HDL (mg/dL) & $41.30 \pm 12.30$ & $45.03 \pm 8.29$ & 0.084 \\
LDL (mg/dL) & $106.51 \pm 31.20$ & $113.98 \pm 31.80$ & 0.266 \\
TG (mg/dL) & $174.72 \pm 74.40$ & $168.92 \pm 56.75$ & 0.773 \\
LVEF (\%) & $56.20 \pm 3.76$ & $57.4 \pm 3.41$ & 0.091 \\
SBP (mm Hg) & $127.00 \pm 7.25$ & $125.51 \pm 6.32$ & 0.293 \\
DBP (mm Hg) & $80.42 \pm 4.66$ & $80.88 \pm 4.19$ & 0.624 \\
Adropin (pg/mL) & $1019.57 \pm 271.01$ & $1151.1 \pm 212.63$ & $\mathbf{0 . 0 1 0}$ \\
Neutrophil to lymphocyte ratio & $2.26 \pm 1.86$ & $2.08 \pm 0.71$ & 0.402 \\
\hline MPV - mean platelet volume; WBC - white blood cell; HDL - high-density lipoprotein; \\
LDL - low-density lipoprotein; TG - triglycerides; LVEF - left ventricular ejection fraction; \\
SBP - systolic blood pressure; DBP - diastolic blood pressure & & \\
\hline
\end{tabular}

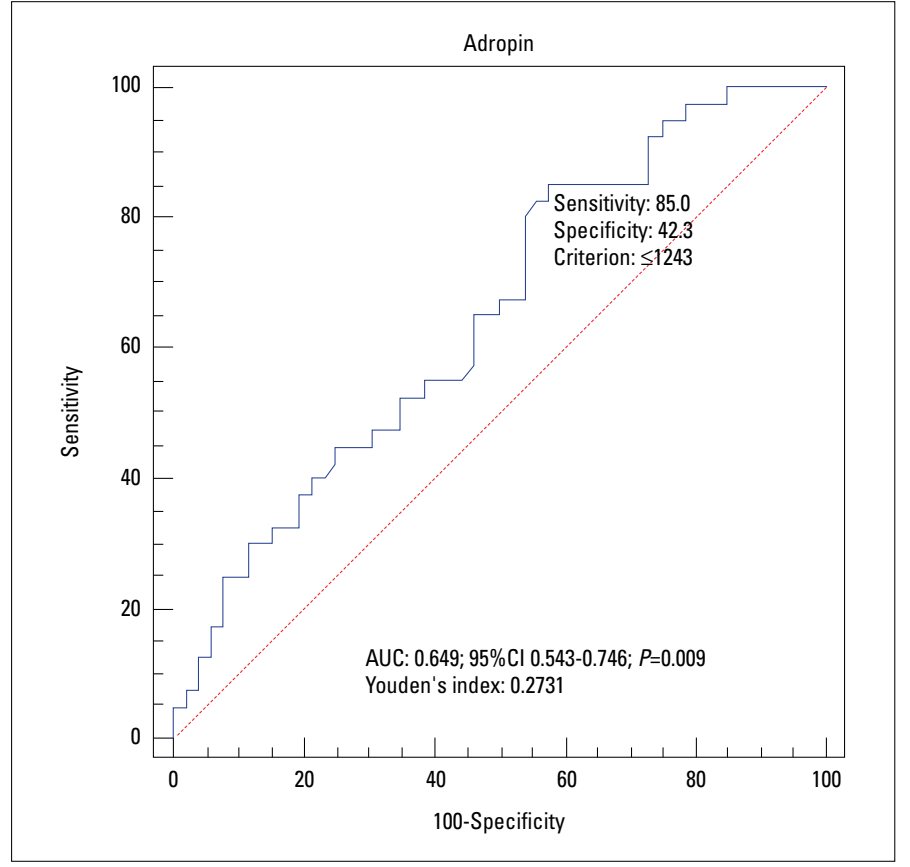

Figure 1. Receiver operating characteristic curve for the determination of the cut-off for adropin level and coronary artery ectasia

Effects of different variables on CAE were calculated using binary logistic regression analysis. Logistic regression (Tables 3 and 4) showed that low serum adropin level was an independent risk factor for isolated CAE [odds ratio (OR): $0.897,95 \% \mathrm{Cl}$ : $0.865-0.949, \mathrm{p}=0.006]$. In addition, high MPV was also identified as an independent risk factor indicating isolated CAE (OR: 3.033, 95\% Cl: $1.526-5.889, \mathrm{p}=0.001$ ).

\section{Discussion}

In this study, we found that patients with isolated CAE had lower serum adropin levels and higher MPV levels compared to subjects with normal coronary arteries. An important feature of our study is that it presents the first evidence of a relationship between serum adropin level and isolated CAE.

CAE is dilation of a major coronary artery to at least 1.5 times the diameter of an adjacent normal segment; a two-fold dilation is called a coronary aneurysm (1). A distorted flow pattern in the dilated coronary segment can cause thrombus formation, which may lead to distal embolization or myocardial infarction (15). Patients with isolated CAE may be asymptomatic or may present with complaints of stable angina pectoris, unstable angina pectoris, or atypical chest pain (16). Increased myocardial ischemia with exercise has also been shown in patients with isolated CAE (17). In addition, it was reported that the 7-year mortality rate of these patients is similar to that of three-vessel coronary artery disease patients followed with medical treatment (18). Thrombotic occlusion in the ectatic region, microembolisms distal to the ectasia, and coronary slow flow are among the causes of 
Table 3. Univariate test results

\begin{tabular}{|c|c|c|c|c|c|c|}
\hline & Coeff. & Standard error & $P$ value & Odds ratio & CI lower limit & CI upper limit \\
\hline Adropin & -0.262 & 0.001 & 0.016 & 0.965 & 0.940 & 0.989 \\
\hline MPV & 0.959 & 0.302 & 0.002 & 2.610 & 1.443 & 4.721 \\
\hline HDL & -0.040 & 0.024 & 0.093 & 0.961 & 0.917 & 1.007 \\
\hline BMI & 0.134 & 0.094 & 0.153 & 1.144 & 0.951 & 1.375 \\
\hline LVEF & -0.102 & 0.061 & 0.093 & 0.903 & 0.802 & 1.017 \\
\hline Use of BB & 0.938 & 0.567 & 0.098 & 2.556 & 0.841 & 7.768 \\
\hline
\end{tabular}

Table 4. Multiple variable test results

\begin{tabular}{|llccccc|}
\hline & Coeff. & Standard error & P value & Odds ratio & Cl lower limit & Cl upper limit \\
\hline Adropin & -0.003 & 0.001 & $\mathbf{0 . 0 0 6}$ & 0.897 & 0.865 & 0.949 \\
MPV & 1.109 & 0.339 & $\mathbf{0 . 0 0 1}$ & 3.033 & 1.526 & 5.889 \\
\hline Coeff. - coefficient expressed in logits; $\mathrm{Cl}$ - 95\% confidence interval for the odds; MPV - mean platelet volume & & \\
\hline
\end{tabular}

increased mortality among these patients. There is no definitive medical treatment for isolated CAE. Some researchers argue that these patients should be given long-term anticoagulant therapy with warfarin (19), while others believe that aspirin alone is sufficient for asymptomatic patients. Due to the vasodilator effect of nitrate on coronary arteries, it is not recommended for CAE patients because it can increase ischemia (20).

Histopathological results are similar in patients with atherosclerosis of the coronary arteries and those with isolated CAE (21). In a study by Malviya et al. (18), Type 4 ectasia was the most common type, while Turan et al. (10) determined that Type 2 was most common. We also observed that Type 2 was the most common type in our study.

Atherosclerotic heart disease is known to be the underlying cause in nearly half of patients with CAE (4) and it is accepted that coronary ectasia occurs as an exaggerated form of the positive remodeling process in these patients (22). In atherosclerosis, spread of plaque material to the tunica media leads to intimal proliferation, which can lead to CAE. Studies conducted to elucidate the mechanism underlying CAE formation have revealed that endothelial damage due to atherosclerosis activates inflammatory mediators like macrophages and metalloproteins, thus leading to degeneration of the tunica media, and these structural changes lead to the release of nitric oxide and other vasodilators from the endothelium, causing vascular dilation in a certain segment (23).

Previous studies on isolated CAE revealed that there is no difference between patients with isolated CAE and control groups in terms of age or DM $(22,24)$. Consistent with those studies, we observed no relationship between isolated CAE and control group in terms of gender and presence of DM. On the other hand, another study by Pinar Bermúdez et al. (25) found that CAE was more common in men and was negatively correlated with DM. However, unlike our patients, that study group was not limited to isolated CAE, but also included a substantial number of patients with severe angiographic stenosis. This may account for the differences between their findings and our own. The negative correlation between CAE and DM in their study may be explained by the impact of DM on the intima layer and its induction of negative remodeling. In addition, endothelium-dependent vasodilatation is impaired in diabetes, which has been attributed to disrupted NO synthesis and inhibition.

Previous studies have also shown that MPV is significantly higher in those with CAE compared to healthy individuals $(26$, 27). Similarly, the MPV values of patients in the isolated CAE group were significantly higher compared to the control group in our study. When their volume increases, platelets become metabolically and enzymatically more active and the activity of thromboxane A2 and the expression of glycoprotein Ilb/IIla increase (28). For these reasons, MPV can be regarded as a marker of platelet activity and has become an indicator of coronary heart disease (29).

Adropin is a protein that is released from the brain, liver, heart, and coronary arteries (9). Adropin contributes to energy homeostasis and reduction of insulin resistance, which are closely linked to the development and progression of atherogenesis (30). In a study conducted on mice, adropin released from the coronary arteries was shown to exert a protective effect on endothelial functions by increasing the expression of endothelial nitric oxide synthase (9). Recent studies have shown adropin to be a key molecule in the regulation of cardiac functions (31). Upregulation of the expression of endothelial 
nitric oxide synthase has been observed in endothelial cells treated with adropin (31). Syndrome $\mathrm{X}$ is a form of coronary artery disease whose etiology is not fully understood, though the underlying cause is believed to be endothelial dysfunction. Celik et al. (22) found that low serum adropin level was an independent risk factor for the development of cardiac syndrome X. In this study, Celik et al. (22) enrolled healthy subjects in the control group and they found Adropin and MPV levels of $3400 \pm 1800 \mathrm{pg} / \mathrm{mL}$ and $9.8 \pm 1.3 \mathrm{fL}$, respectively. Other biomarker levels were within the normal range as in the control group of our study. Endothelial dysfunction, indicated by molecules such as endocan and nitric oxide, has been linked to isolated CAE in previous studies $(10,11)$.

In our study, low levels of adropin and high levels of MPV were found to be independent risk factors for isolated CAE. In a previous study, there was a relationship between endothelial dysfunction and high MPV levels (27). We think that low adropin levels may have caused some increase in MPV values by contributing to endothelial dysfunction and CAE. Low adropin may lead to intravascular thrombosis of ectatic vessel segments, which increases platelet consumption and reduces their number. We believe that this stimulates bone marrow to produce larger platelets, thus contributing to increasing of MPV. High MPV in these patients reflects changes in activity and platelet aggregation. As a result, microvascular dysfunction and increased platelet activity may result in thrombus formation in patients with ectatic vessels. However, our correlation analysis revealed that there is no significant relationship between adropin and MPV. Further studies are needed to examine the relationship between adropin level and MPV.

To our knowledge, there are no previous studies in the literature that investigate the relationship between serum adropin level and isolated CAE. Our results may contribute to etiopathogenesis of CAE and pathophysiological mechanisms of increased prevalence of cardiovascular morbidity and mortality risk in these patients. The results of our study indicated that serum adropin levels below $1234 \mathrm{pg} / \mathrm{mL}$ are associated with isolated CAE. In light of these findings, we conclude that a low serum adropin level, which is associated with endothelial dysfunction, and an elevated MPV are independent risk factors for the development of CAE. MPV and serum adropin levels are simple and cost-effective markers that can be used to analyze endothelial dysfunction and their relation with isolated CAE.

\section{Study limitations}

The main limitations of our study are the relatively small number of patients and the lack of long-term patient follow-up. The specific mechanism of isolated CAE formation remains unclear. However, based on previous studies demonstrating the major role of endothelial dysfunction in isolated CAE development, CAE is regarded as a type of atherosclerotic coronary artery disease. Nevertheless, considering that endothelial dysfunction can also be seen in coronary artery pathologies other than CAE, results from further studies on the relationship between isolated CAE and endothelial dysfunction are needed to draw a definitive conclusion. In addition, the presence of coronary ectasia was assessed visually in our study, and a quantitative method which more clearly demonstrates ectopic presence, such as intravascular ultrasound, was not used.

\section{Conclusion}

To the best of our knowledge, there are no previous studies in the literature that investigate the relationship between serum adropin level and isolated CAE. The results of our study indicate that low serum adropin level is associated with isolated CAE. In light of these findings, we conclude that a low serum adropin level, which is associated with endothelial dysfunction, and an elevated MPV are independent risk factors for the development of CAE.

Conflict of interest: None declared.

Peer-review: Externally peer-reviewed.

Authorship contributions: Concept - B.Ö., Ö.0̈.; Design - B.Ö., A.Ç.; Supervision - A.Ç., I.T.0̈.; Funding - B.Ö., Ö.Ö., H.Y.Y., M.K.Ö.; Materials - B.Ö., Ö.Ö., Ş.B.; Data collection and/or processing - B.Ö., Ö.0̈., H.Y.Y., M.K.Ö.; Analysis and/or interpretation - B.Ö., Ö.0̈., S..B.; Literature search - B.Ö., H.Y.Y., M.K.Ö.; Writing - B.0̈.; Critical review - 0̈.0̈., A.Ç., I.T.0̈.

\section{References}

1. Swanton RH, Thomas ML, Coltart DJ, Jenkins BS, Webb-Peploe MM, Williams BT. Coronary artery ectasia--a variant of occlusive coronary arteriosclerosis. Br Heart J 1978; 40: 393-400. [CrossRef]

2. Hartnell GG, Parnell PM, Pridie RB. Coronary artery ectasia, its prevalence and clinical significance in 4993 patients. Br Heart $\mathrm{J}$ 1985; 54: 392-5. [CrossRef]

3. [No authors listed]. National Heart, Lung, and Blood Institute Coronary Artery Surgery Study. A multicenter comparison of the effects of randomized medical and surgical treatment of mildly symptomatic patients with coronary artery disease, and a registry of consecutive patients undergoing coronary angiography. Circulation 1981; 63 (6 Pt 2): I1-81.

4. Demopoulos VP, Olympios CD, Fakiolas CN, Pissimissis EG, Economides NM, Adamopoulou E, et al. The natural history of aneurysmal coronary artery disease. Heart 1997; 78: 136-41. [CrossRef]

5. Pohl U, Busse R. Endothelium-dependent modulation of vascular tone and platelet function. Eur Heart J 1990; 11 Suppl B: 35-42.

6. Stehouwer CD, Lambert J, Donker AJ, van Hinsbergh VW. Endothelial dysfunction and pathogenesis of diabetic angiopathy. Cardiovasc Res 1997; 34: 55-68. [CrossRef]

7. Lu J, Xiang G, Liu M, Mei W, Xiang L, Dong J. Irisin protects against endothelial injury and ameliorates atherosclerosis in apolipoprotein E-Null diabetic mice. Atherosclerosis 2015; 243: 438-48. [CrossRef]

8. Davis MJ, Hill MA. Signaling mechanisms underlying the vascular myogenic response. Physiol Rev 1999; 79: 387-423. [CrossRef] 
9. Lovren F, Pan Y, Quan A, Singh KK, Shukla PC, Gupta M, et al. Adropin is a novel regulator of endothelial function. Circulation 2010; 122(11 Suppl): S185-92. [CrossRef]

10. Turan T, Akyuz AR, Aykan AC, Kul S, Cirakoglu OF, Aslan A0, et al. Plasma Endocan Levels in Patients With Isolated Coronary Artery Ectasia. Angiology 2016; 67: 932-6. [CrossRef]

11. Gürlek A, Esenboğa $K$, Özcan ÖU, Çiçek ÖF, Arıbal Ayral P, Özelçi Kavas G, et al. Serum nitric oxide levels in patients with coronary artery ectasia. Anatol J Cardiol 2016; 16: 947-52. [CrossRef]

12. Markis JE, Joffe CD, Cohn PF, Feen DJ, Herman MV, Gorlin R. Clinical significance of coronary arterial ectasia. Am J Cardiol 1976; 37: 217-22. [CrossRef]

13. Vittinghoff E, Glidden DV, Shibosci SC, McCulloch CE. Regression Methods in Biostatistics. Springer, 2004; 133-56.

14. Ruopp MD, Perkins NJ, Whitcomb BW, Schisterman EF. Youden Index and Optimal Cut-Point Estimated from Observations Affected by a Lower Limit of Detection. Biom J 2008; 50: 419-30. [CrossRef]

15. Glickel SZ, Maggs PR, Ellis FH Jr. Coronary artery aneurysm. Ann Thorac Surg 1978; 25: 372-6. [CrossRef]

16. Wenger NK. Nonatherosclerotic causes of myocardial ischemia and necrosis. In: Hurst The Heart, 4th edn. New York: McGrow-Hill; 1978: pp.1345-62.

17. Sayin T, Döven O, Berkalp B, Akyürek O, Güleç $S$, Oral D. Exercise induced myocardial ischemia in patients with coronary artery ectasia without obstructive coronary artery disease. Int J Cardiol 2001; 78: 143-9. [CrossRef]

18. Malviya A, Jha PK, Mishra A. Isolated coronary artery ectasia: Clinical, angiographic, and follow up characteristics. Indian Heart $\mathrm{J}$ 2017; 69: 619-23. [CrossRef]

19. Fukuhara S, Takase E, Fujimoto T, Takami Y, Yamamoto K, Nishida T, et al. Coronary ectasia resulting in thrombotic coronary occlusion after warfarin interruption: a case report. J Cardiol 2005; 46: 195-200.

20. Krüger D, Stierle U, Herrmann G, Simon R, Sheikhzadeh A. Exerciseinduced myocardial ischemia in isolated coronary artery ectasias and aneurysms ("dilated coronopathy"). J Am Coll Cardiol 1999; 34: 1461-70. [CrossRef]
21. Swanton RH, Thomas ML, Coltart DJ, Jenkins BS, Webb-Peploe MM, Williams BT. Coronary artery ectasia, a variant of occlusive coronary arteriosclerosis. Br Heart J 1978; 40: 393-400. [CrossRef]

22. Celik S, Erdoğan T, Kasap H, Kaplan S, Durmuş I, Gedik O, et al. Carotid intima-media thickness in patients with isolated coronary artery ectasia. Atherosclerosis 2007; 190: 385-7. [CrossRef]

23. Davies MJ. Glagovian remodelling, plaque composition, and stenosis generation. Heart 2000; 84: 461-2. [CrossRef]

24. Dursun H, Onrat E, Ozkececi G, Akcı 0, Avsar A, Melek M. Endothelial Dysfunction in Patients with Isolated Coronary Artery Ectasia: Decreased flow-mediated dilatation in the brachial artery. Biomedical Research 2015; 26: 328-32.

25. Pinar Bermúdez E, López Palop R, Lozano Martínez-Luengas I, Cortés Sánchez R, Carrillo Sáez P, Rodríguez Carreras R, et al. Coronary ectasia: prevalence, and clinical and angiographic characteristics. Rev Esp Cardiol 2003; 56: 473-9. [CrossRef]

26. Varol E, Akcay S, Ozaydin M, Erdogan D, Dogan A. Mean platelet volume in patients with coronary artery ectasia. Blood Coagul Fibrinolysis 2009; 20: 321-4. [CrossRef]

27. Sen N, Tavil Y, Yazici HU, Hizal F, Açikgöz SK, Abaci A, et al. Mean platelet volume in patients with coronary artery ectasia. Med Sci Monit 2007; 13: CR356-9.

28. Martin JF, Trowbridge EA, Salmon G, Plumb J. The biological significance of platelet volume: its relationship to bleeding time, platelet thromboxane B2 production and megakaryocyte nuclear DNA concentration. Thromb Res 1983; 32: 443-60. [CrossRef]

29. Erhart S, Beer JH, Reinhart WH. Influence of aspirin on platelet count and volume in humans. Acta Haematol 1999; 101: 140-4.

30. Kumar KG, Trevaskis JL, Lam DD, Sutton GM, Koza RA, Chouljenko $\mathrm{VN}$, et al. Identification of adropin as a secreted factor linking dietary macronutrient intake with energy homeostasis and lipid metabolism. Cell Metab 2008; 8: 468-81. [CrossRef]

31. Lovren F, Pan Y, Quan A, Singh KK, Shukla PC, Gupta M, et al. Adropin is a novel regulator of endothelial function. Circulation 2010; 122(11 Suppl): S185-92. [CrossRef] 